\title{
Descripción epidemiológica del reservorio de rabia en murciélagos de la Región Metropolitana. Chile. 2000-2009
}

\author{
Myriam Favi C., Ángela Bassaletti C., Javier López D., Luis Rodríguez A. y Verónica Yung P.
}

\section{Epidemiological description of rabies reservoir in bats in the Metropolitan Region. Chile. 2000-2009}

In Chile, in 1985 rabies was detected in insectivorous bats. Since then the epidemiological surveillance activities was extended to these species and the epidemiological pattern was characterized as endemic in bats. In this study we analyzed positive rabies cases in the Metropolitan Region between 2000 and 2009. We identified 325 cases of rabies in 11.472 analyzed samples. We determined an increase of positivity cases in bats between the years of the study. Places with the highest number of positives cases were Las Condes, Santiago, Providencia, Puente Alto and Nuñoa. In 147 cases we identify the circumstances in which the bat was found: 89 inside, 45 outside the building and 13 in public spaces. In 39 cases there was contact with humans or animals. These results reinforce the relevance of educating the population against the contact with bats and allow health authorities to take early surveillance and control measures.

Key words: Rabies, bats, rabies epidemiology.

Palabras clave: Rabia, murciélagos, epidemiología.

\section{Introducción}

L a rabia es una zoonosis milenaria de gran importancia en salud pública, ganadería y economía, por su amplia distribución y propagación entre reservorios animales. Esta enfermedad sigue siendo una de las causas virales de muerte más común en el mundo en vías de desarrollo ${ }^{1}$.

La rabia es una infección aguda del sistema nervioso central, casi siempre mortal. El virus comúnmente se transmite a los humanos por mordida de un animal rabioso o por el contacto con la saliva de éste ${ }^{2}$.

En América, durante la última década, el promedio anual de rabia humana fue de 61 casos y el de rabia canina de 1.759 casos, siendo la fuente de contagio tanto animales domésticos como silvestres ${ }^{3}$.

Eliminar la rabia humana transmitida por perros ha sido un gran desafío para la Región de Las Américas. Esta decisión fue tomada en la década de los 80 por todos los estados miembros de la Organización Panamericana de la Salud (OPS), disminuyendo durante el período 1982-2003 el número de casos de rabia humana en $91 \%{ }^{4}$.

En Chile, la rabia ha experimentado una disminución significativa en los últimos años, cambiando su patrón epidemiológico desde una forma endémica en la década de 1950 a 1960, con numerosos casos humanos y animales, a la presentación de casos esporádicos en la década de $1970^{5}$ y finalmente a la ausencia de casos humanos desde
1972 hasta 1996, donde se registró el último caso de rabia en el país, cuya fuente de contagio fue un murciélago insectívoro ${ }^{6}$.

En animales domésticos, se presentaron casos esporádicos en la década del 80 , sin que la fuente de infección pudiera ser identificada. Estos casos tuvieron bajo poder epidémico presentándose incluso un silencio epidemiológico en los años 1982 y 1984. Desde 1990 se encuentra interrumpida la circulación de la variante 1 canina. Todos los casos en animales domésticos detectados posteriormente, corresponden a variantes antigénicas de murciélagos insectívoros ${ }^{7}$.

En 1985 se detectó por primera vez rabia en murciélagos insectívoros de la especie Tadarida brasiliensis ${ }^{8}$, lo que motivó el inicio de la vigilancia epidemiológica en murciélagos sospechosos y comenzó además un programa de captura masiva de estos quirópteros ${ }^{9}$.

El reconocimiento de los murciélagos como reservorios de la enfermedad hizo que se ampliaran las acciones de vigilancia epidemiológica hacia esas especies. A partir de entonces, el patrón epidemiológico de la rabia en Chile se ha caracterizado por una endemia en quirópteros ${ }^{7}$.

El riesgo para el hombre de contraer rabia subsistirá mientras exista circulación de virus entre los murciélagos, que se encuentran ampliamente distribuidos en el país. El análisis epidemiológico de los casos de rabia en la Región Metropolitana (RM) nos permitirá conocer las especies involucradas, la existencia de contactos humanos
Instituto de Salud Pública de Chile (MFC, LRA, VYP). Universidad Santo Tomás Facultad de Medicina Veterinaria ( $A B C$, JLD).

Los autores declaran no tener conflictos de interés

Recibido: 30 de septiembre de 2010 Aceptado: 8 de marzo de 2011

Correspondencia a: Verónica Yung Peredo vyung@ispch.cl 
o animales y los sectores con ocurrencia de casos, lo que redundará en un mayor conocimiento y prevención de la enfermedad.

\section{Tabla 1. Positividad de muestras para virus rabia en murciélagos, análisis} por años. Región Metropolitana, Chile. 2000 al 2009

\begin{tabular}{|cccc|}
\hline Año & Total muestras & Muestras positivas & Positividad (\%) \\
\hline 2000 & 1.111 & 19 & 1,7 \\
\hline 2001 & 1.003 & 18 & 1,8 \\
\hline 2002 & 1.207 & 47 & 3,9 \\
\hline 2003 & 1.329 & 28 & 2,1 \\
\hline 2004 & 1.524 & 39 & 2,6 \\
\hline 2005 & 1.736 & 46 & 2,6 \\
\hline 2006 & 1.236 & 42 & 3,4 \\
\hline 2007 & 846 & 34 & 4,01 \\
\hline 2008 & 945 & 25 & 2,6 \\
\hline 2009 & 535 & 27 & 5,04 \\
\hline Total & 11.472 & 325 & 2,83 \\
\hline
\end{tabular}

Tabla 2. Regresión Simple-Proporción de positivos versus año STATGRAPHICS Centurión XV

Análisis de regresión - Modelo doble reciproco: $Y=1 /(a+b / X)$

Variable dependiente: Proporción Positivos

Variable independiente: Año

\begin{tabular}{ccccc} 
Parámetro & Estimado & Error Estándar & T Estadístico & Valor-P \\
\hline Intercepto & $-6437,02$ & 2049,28 & $-3,14112$ & 0,0138 \\
\hline Pendiente & $1,29784 \mathrm{E} 7$ & $4,10776 \mathrm{E} 6$ & 3,15947 & 0,0134 \\
\hline $\begin{array}{l}\text { Modelo optimizado de regresión } \\
\text { Proporción de Positivos }=1 /(-6437,02\end{array}$ & & & \\
\hline
\end{tabular}

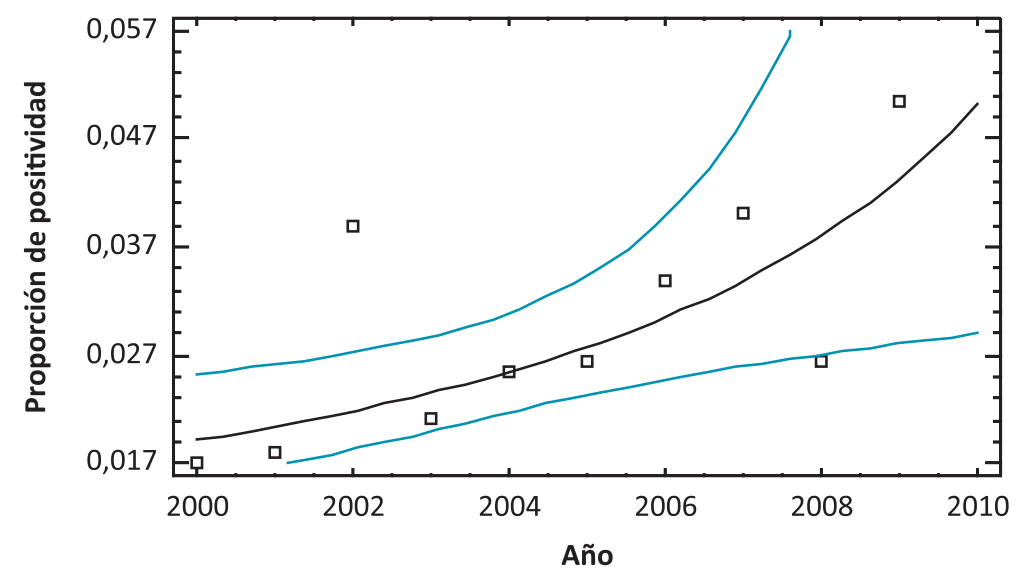

Figura 1. Proporción de murciélagos positivos a rabia por año. Instituto de Salud Pública de Chile.

\section{Materiales y Métodos}

Se utilizaron los registros históricos nacionales de la Sección Rabia del Instituto de Salud Pública de Chile con los que se construyó una base de datos con las muestras recepcionadas provenientes de la $\mathrm{RM}$, entre los años 2000 y 2009, y luego se trabajó con el formulario de recepción de cada muestra positiva a rabia, que contenía la siguiente información: fecha de recepción, localidad de procedencia, especie del murciélago, categorización epidemiológica como sospecha o vigilancia, contactos humanos o animales.

Una vez obtenidos los datos de cada muestra positiva, se ordenaron en un archivo Excel por fecha de recepción y se resumió la información con tablas dinámicas para detectar tendencias, obteniendo sumas parciales y totales por año, comunas de la RM y especies de murciélagos, para así estudiar sus interacciones. Una vez finalizado este proceso, la información se ingresó a paquetes estadísticos STATA versión 9.1 y STATGRAPHICS centurión XV ${ }^{10,11}$.

\section{Resultados}

De un total de 11.472 muestras procedentes de la RM entre los años 2000 y 2009, se detectaron 325 (2,83\%) muestras positivas a rabia correspondientes a especies de murciélagos insectívoros.

En la Tabla 1 se observa el total de muestras analizadas por año y el número de muestras positivas correspondientes en su totalidad a murciélagos insectívoros. El porcentaje de positividad varió entre 1,7\% y 5,04\% durante los años en estudio.

La Tabla 2 presenta los resultados de ajustar un modelo doble inverso de regresión para describir la relación entre porcentaje de positividad y año. Para detectar tendencias de positividad, se efectuaron análisis de regresión lineal de mínimos cuadrados utilizando el programa estadístico Statgraphics centurión XV. La ecuación del modelo ajustado es:

Proporción de positivos $=$ 1/(-6437,02 + 1,29784E7/año)

En la Figura 1 se observa una curva de regresión, utilizando el modelo doble inverso, el cual expresa un aumento de positividad en los murciélagos entre los años 2000 y 2009, ( $\mathrm{p}=0,138$ ) y una pendiente de 0,0134 (Tabla 2), valor que sugiere que tanto pendiente como el intercepto son estadísticamente significativos.

Puesto que el valor-P en la Tabla 3 (ANOVA) es 0,0134, existe una relación estadísticamente significativa entre proporción de positivos y año con un nivel de confianza del 95,0\%, indicando que el modelo de regresión que se 


\begin{tabular}{|c|c|c|c|c|c|}
\hline Fuente & Suma de cuadrados & Grado de libertad & Cuadrado medio & Razón-F & Valor-P \\
\hline Modelo & 860,743 & 1 & 860,743 & 9,98 & 0,0134 \\
\hline Residuo & 689,817 & 8 & 86,2271 & & \\
\hline Total (Corr.) & $1.550,56$ & 9 & & & \\
\hline \multicolumn{3}{|c|}{$\begin{array}{l}\text { Coeficiente de correlación }=0,745062 \\
\text { R-cuadrada }=55,5118 \text { por ciento } \\
\text { R-cuadrado (ajustado para grado de libertad) }=49,899 \text { por ciento } \\
\text { Error estándar del est. }=9,317\end{array}$} & \multicolumn{3}{|c|}{$\begin{array}{l}\text { Error absoluto medio }=6,30843 \\
\text { Estadístico Durbin-Watson }=2,73744(P=0,8089) \\
\text { Autocorrelación de residuos en retraso } 1=-0,404606\end{array}$} \\
\hline
\end{tabular}

Tabla 4. Casos positivos para rabia por especie de murciélago. Región Metropolitana, Chile. 2000-2009

\begin{tabular}{|lcc|}
\hline Especie de murciélago & $\begin{array}{c}\text { Casos } \\
\text { positivos }\end{array}$ & $\begin{array}{c}\text { Positividad } \\
\text { (\%) }\end{array}$ \\
\hline Tadarida brasiliensis & 297 & 91,3 \\
\hline Lasiurus cinereus & 19 & 5,84 \\
Lasiurus boreales & 4 & 1,23 \\
Histiotus macrotes & 3 & 0,92 \\
Myotis chiloensis & 2 & 0,61 \\
Total & 325 & 100 \\
\hline
\end{tabular}

empleó era el adecuado. El estadístico R-Cuadrada indica que el modelo ajustado explica 55,5\% de la variabilidad en Proporción de positivos. El coeficiente de correlación es igual a 0,745, indicando una relación moderadamente fuerte entre las variables. El error estándar del estimado indica que la desviación estándar de los residuos es 9,3. El error absoluto medio de 6,308 es el valor promedio de los residuos. El estadístico de Durbin-Watson examina los residuos para determinar si hay alguna correlación significativa basada en el orden en el que se presentan en el archivo de datos, puesto que el valor-P es mayor que 0,05; no hay indicación de una auto-correlación serial en los residuos con un nivel de confianza de 95,0\%.

En la Tabla 4 se identifica el número de casos positivos por especie de murciélagos, el mayor porcentaje (91,3\%) se obtuvo en la especie T. brasiliensis, con 297 casos, mientras que el menor porcentaje $(0,61 \%)$ se obtuvo en murciélagos de la especie Myotis chiloensis con dos casos.

En la Tabla 5 se observan los casos de rabia por Servicio de Salud Metropolitano donde se ve la positividad en relación a la comuna. Del total de casos positivos analizados de la RM, las comunas de Las Condes, Santiago, Providencia, Puente Alto y Ñuñoa presentan el mayor número de casos positivos a rabia. Sin embargo, si se analizan los porcentajes de positividad en relación a las muestras analizadas por comuna, las comunas con bajo número de muestras analizadas presentan un alto
Tabla 5. Casos diagnosticados positivos a virus rabia por Servicio de Salud. Región Metropolitana, Chile. 2000-2009

\begin{tabular}{|c|c|c|c|c|}
\hline $\begin{array}{l}\text { Servicios de Salud } \\
\text { Región Metropolitana }\end{array}$ & Comunas & $\begin{array}{l}\text { Casos } \\
\text { positivos }\end{array}$ & $\begin{array}{c}\text { Total } \\
\text { analizado }\end{array}$ & $\begin{array}{c}\text { Positividad } \\
\text { (\%) }\end{array}$ \\
\hline Oriente & $\begin{array}{l}\text { Las Condes } \\
\text { Providencia } \\
\text { Ñuñoa } \\
\text { Vitacura } \\
\text { Peñalolén } \\
\text { La Reina } \\
\text { Macul } \\
\text { Lo Barnechea }\end{array}$ & $\begin{array}{l}61 \\
24 \\
18 \\
14 \\
13 \\
5 \\
5 \\
1\end{array}$ & $\begin{array}{l}2.038 \\
775 \\
438 \\
260 \\
456 \\
186 \\
328 \\
83\end{array}$ & $\begin{array}{l}3,0 \\
3,1 \\
4,1 \\
5,4 \\
2,9 \\
2,7 \\
1,5 \\
1,2\end{array}$ \\
\hline Central & $\begin{array}{l}\text { Santiago } \\
\text { Maipú } \\
\text { Estación Central } \\
\text { Cerrillos }\end{array}$ & $\begin{array}{c}40 \\
11 \\
4 \\
1\end{array}$ & $\begin{array}{c}775 \\
286 \\
64 \\
82\end{array}$ & $\begin{array}{l}5,2 \\
3,9 \\
6,3 \\
1,2\end{array}$ \\
\hline Sur-Oriente & $\begin{array}{l}\text { Puente Alto } \\
\text { La Florida } \\
\text { La Pintana } \\
\text { Pirque } \\
\text { Sn. José de Maipo } \\
\text { San Ramón }\end{array}$ & $\begin{array}{c}21 \\
11 \\
5 \\
2 \\
1 \\
1\end{array}$ & $\begin{array}{c}505 \\
326 \\
253 \\
46 \\
101 \\
91\end{array}$ & $\begin{array}{l}4,2 \\
3,4 \\
2,0 \\
4,4 \\
1,0 \\
1,1\end{array}$ \\
\hline Occidente & $\begin{array}{l}\text { Melipilla } \\
\text { Talagante } \\
\text { Pudahuel } \\
\text { Cerro Navia } \\
\text { Peñaflor } \\
\text { María Pinto } \\
\text { Renca } \\
\text { Lo Prado } \\
\text { Padre Hurtado }\end{array}$ & $\begin{array}{l}10 \\
7 \\
6 \\
4 \\
2 \\
3 \\
1 \\
1 \\
1\end{array}$ & $\begin{array}{c}368 \\
274 \\
136 \\
61 \\
125 \\
134 \\
68 \\
85 \\
257\end{array}$ & $\begin{array}{l}2,7 \\
2,5 \\
4,4 \\
6,6 \\
1,6 \\
2,2 \\
1,5 \\
1,2 \\
0,3\end{array}$ \\
\hline Sur & $\begin{array}{l}\text { San Bernardo } \\
\text { Buin } \\
\text { Paine } \\
\text { Pedro Aguirre Cerda } \\
\text { Lo Espejo } \\
\text { San Miguel } \\
\text { Calera de Tango } \\
\text { La Cisterna }\end{array}$ & $\begin{array}{l}8 \\
6 \\
4 \\
3 \\
2 \\
1 \\
1 \\
1\end{array}$ & $\begin{array}{c}297 \\
194 \\
114 \\
41 \\
48 \\
98 \\
172 \\
25\end{array}$ & $\begin{array}{l}2,7 \\
3,1 \\
3,5 \\
7,3 \\
4,2 \\
1,0 \\
0,6 \\
4,0\end{array}$ \\
\hline Norte & $\begin{array}{l}\text { Colina } \\
\text { Quilicura } \\
\text { Recoleta } \\
\text { Lampa } \\
\text { Independencia } \\
\text { Conchalí } \\
\text { Huechuraba }\end{array}$ & $\begin{array}{l}6 \\
5 \\
5 \\
3 \\
3 \\
2 \\
2\end{array}$ & $\begin{array}{c}311 \\
122 \\
89 \\
199 \\
151 \\
183 \\
37\end{array}$ & $\begin{array}{l}1,9 \\
4,1 \\
5,6 \\
1,5 \\
2,0 \\
1,1 \\
5,4\end{array}$ \\
\hline
\end{tabular}


Tabla 6. Casos positivos para virus rabia en murciélagos, según tipo de muestras. Región Metropolitana, Chile. 2000-2009

\begin{tabular}{|lccccc|}
\hline $\begin{array}{c}\text { Tipo de } \\
\text { muestra }\end{array}$ & \multicolumn{2}{c}{ Casos positivos } & \multicolumn{2}{c|}{ Total de muestras } & $\begin{array}{c}\text { Positividad } \\
\text { (\%) }\end{array}$ \\
\hline Sospecha & 321 & $98,8 \%$ & 4.937 & $43 \%$ & 6,5 \\
\hline Vigilancia & 4 & $1,2 \%$ & 6.535 & $57 \%$ & 0,06 \\
\hline Total & 325 & $100 \%$ & 11.472 & $100 \%$ & 2,8 \\
\hline
\end{tabular}

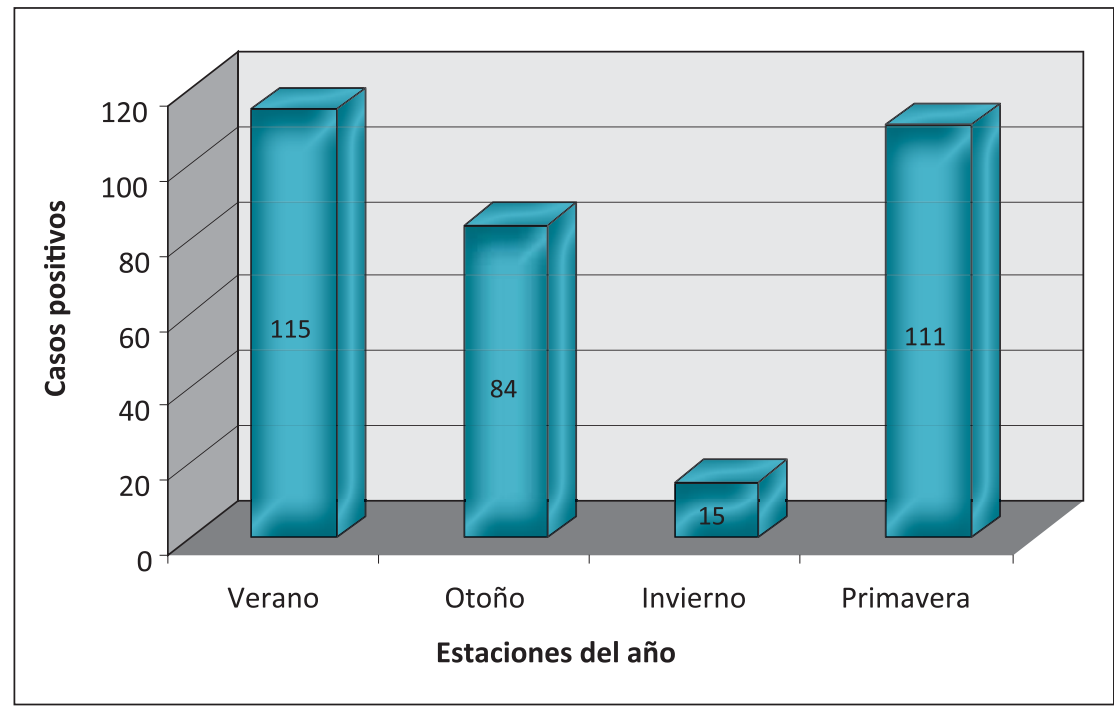

Figura 2. Casos positivos para virus rabia en murciélagos, por estaciones del año. Región Metropolitana, Chile. 2000-2009.

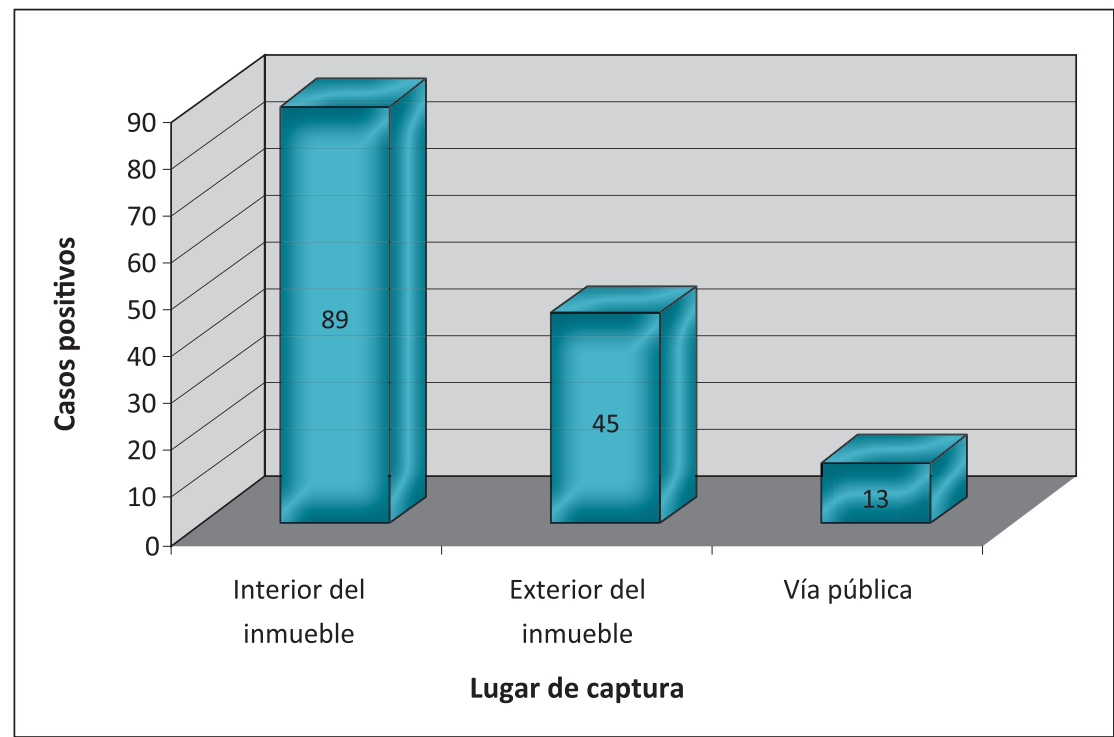

Figura 3. Casos de murciélagos positivos según lugar de captura. porcentaje de positividad, como Pedro Aguirre Cerda (7,3\%), Cerro Navia (6,6\%), Estación Central (6,3\%), Recoleta (5,6\%) y Vitacura (5,4\%).

En la Tabla 6 se observan los casos positivos obtenidos por sospecha (demanda espontánea) y por vigilancia (captura). Del total de muestras recepcionadas como sospecha, que representa $43 \%$ del total, $6,5 \%$ correspondió a casos positivos a rabia; sin embargo, de las muestras recepcionadas como vigilancia que representan el $57 \%$ del total, $0,06 \%$ fue positivo a rabia. Del total de positivos, $98,7 \%$ correspondió a casos por sospecha y 1,2\% a vigilancia.

La Figura 2 muestra los casos de murciélagos positivos según las estaciones del año, lo que permitió señalar que existe una estacionalidad. La mayor positividad en murciélagos se presenta en la época estival, correspondiendo a 226 casos en primavera-verano y a 99 casos en otoño-invierno.

En la Figura 3 se observan los casos positivos según el lugar de captura. De 325 fichas, en 147 se señaló el lugar donde se encontró el murciélago. Al interior del inmueble (departamentos, casas, colegios, universidades, oficinas, jardines infantiles y hospitales) fueron encontrados 89 murciélagos con rabia, mientras que en el exterior (patio, antejardín, estacionamientos, piscinas) fueron encontrados 45 murciélagos con rabia. En la vía pública (calles y sectores rurales) se encontraron 13 murciélagos con rabia.

De los 325 casos de murciélagos positivos a rabia, en 39 se describe algún tipo de contacto: con personas, 13 ocurrieron en niños y en 2 de ellos existió una posible mordida; con animales, estos se refieren a especies caninas y felinas.

\section{Discusión}

Desde el año 1985, cuando se detecta el primer caso de rabia en murciélagos insectívoros en la comuna de La Pintana, la situación epidemiológica de la rabia en Chile cambió, desde la presentación de casos domésticos en forma esporádica a una endemia en murciélagos, cuyo promedio de positividad ha ido aumentando desde 20 casos anuales a 70 en los últimos años. Este aumento se observó en la RM con 38,6\% en relación a los casos de rabia de todo el país ${ }^{12}$.

En Chile existen 11 especies de murciélagos y de ellas sólo seis habitan en la $\mathrm{RM}^{13}$. En este estudio se determinaron cinco especies de murciélagos positivas al virus de la rabia, siendo $T$. brasiliensis el reservorio más importante en el país ${ }^{14}$.

Por medio de la caracterización viral se ha podido comprobar que la circulación del virus rábico variante canina no está circulando desde el año $1990^{7}$, los casos de rabia de animales domésticos detectados en el país después de 1990 han sido provocados por variante murciélago; 
de ahí la importancia de tomar las medidas de control necesarias ya que la rabia se ha perpetuado en Chile con los murciélagos.

Las comunas que tienen un mayor porcentaje de positividad no son las que tienen mayor número de muestras analizadas; es el caso de Vitacura con un 5,4\% de positividad (14/260), Cerro Navia (4/61), Estación Central (4/64) y Huechuraba (2/37), en contraste con comunas como Las Condes con un alto número de analizados y un bajo porcentaje de positividad (61/2.038). Este bajo porcentaje de positividad está influenciado por la cantidad de ejemplares obtenidos por capturas masivas en colonias de murciélagos, sobre todo en época estival, lo mismo ocurre en Santiago, Providencia, Puente Alto y Ñuñoa ${ }^{15}$.

En las colonias de murciélagos, un porcentaje muy bajo se encuentra infectado y los individuos enfermos son excluidos de las mismas ${ }^{16}$. El animal enfermo sale de su colonia, pudiendo desplazarse en un radio de $20 \mathrm{~km}$ o más ${ }^{17}$, por lo cual el agrupamiento de la enfermedad no se limita a las zonas de colonización. Esto explicaría los casos aislados de murciélagos diagnosticados positivos en algunas localidades, donde no existía historial.

Estudios anteriores de Hott $^{17}$ y Rivas ${ }^{18}$ analizan en forma espacio-temporal los murciélagos positivos a rabia en la RM, concluyendo que es en el sector oriente de la ciudad donde existe la mayor cantidad de casos.

En la época invernal existe una disminución de los casos de rabia lo que se asocia a la etología de estos murciélagos, ya que en invierno entran en una etapa de letargo y su metabolismo se reduce al mínimo hasta la primavera. Este estado de sopor ocurre cuando las temperaturas ambientales caen por debajo del límite inferior de termo-neutralidad ${ }^{13}$. El entrar o no en sopor depende de la disponibilidad de alimento; en invierno, los insectos disminuyen, lo que provocaría una disminución de denuncias y positividad. En la época estival la gran cantidad de insectos permite que éstos salgan a cazar y se vean en abundancia en zonas rurales y urbanas ${ }^{19}$. Según un estudio de Wayne ${ }^{20}$, las enfermedades que se presentan en animales silvestres con hábitos estacionales tienden a mostrar esta misma tendencia, lo que se evidencia en este estudio.

El hallazgo de casos positivos a rabia por sospecha $(6,5 \%)$ tienen una gran relevancia en la salud pública; por lo tanto, es fundamental educar a la población acerca de las conductas a seguir frente a ciertas situaciones, como por ejemplo las mordeduras imperceptibles de los murciélagos insectívoros, cuyos dientes son muy pequeños y afilados. En relación a los casos de rabia en murciélagos encontrados al interior del inmueble, en 13 casos hubo contactos humanos y dos niños fueron mordidos por murciélago. Gracias a una intervención y diagnóstico oportunos se realizó la vacunación anti-rábica post exposición y se tomaron las medidas epidemiológicas necesarias. Por lo tanto, es importante que la comunidad informe a la autoridad sanitaria el hallazgo de murciélagos encontrados en lugares no habituales (dentro de las casas), de manera que estos hechos no pasen desapercibidos y así tomar las medidas epidemiológicas necesarias para las personas o animales que hayan estado en contacto. En caso contrario, podríamos estar frente a un probable contagio, sin tener la fuente de infección claramente identificada, como ha ocurrido en varios casos de rabia humana en E.U.A. donde la fuente de infección ha sido un murciélago insectívoro ${ }^{21,22}$.

Agradecimientos. Al personal de la Sección Rabia del Instituto de Salud Publica, en especial a Cristina Toledo por su importante colaboración.

\section{Resumen}

En Chile, en 1985, se detectó por primera vez rabia en murciélagos insectívoros. Desde entonces, las acciones de vigilancia epidemiológica se ampliaron hacia estas especies, caracterizándose el patrón epidemiológico como una endemia en quirópteros. En este estudio se analizaron epidemiológicamente los casos positivos a rabia en la Región Metropolitana, entre los años 2000 y 2009. Se identificaron 325 casos de rabia en murciélagos de un total de 11.472 analizados. Se determinó un aumento de positividad en los murciélagos entre los años analizados. Las comunas con mayor número de positivos fueron Las Condes, Santiago, Providencia, Puente Alto y Ñuñoa. En 147 casos se señalan las circunstancias en que se encontró el murciélago: 89 al interior, 45 al exterior del inmueble y 13 en la vía pública. En 39 casos hubo contacto con personas o animales. Estos resultados reafirman la importancia de la educación de la población frente al contacto con murciélagos y permiten a las autoridades sanitarias tomar las medidas de vigilancia y control en forma oportuna.

\section{Referencias}

1.- $\quad$ Bassin SL, Rupprecht CE, Bleck TP. Rhabdoviruses In Mandell, Douglas and Bennett's Principles and Practice of Infectious Diseases. Mandell GL, Bennett JE,Dolin R, eds. $7^{\text {th }}$ ed. 2010. Churchill Livingstone Elsevier pp.
2249-58.

2.- Brooks Geo F, et al. Rabia, infecciones por virus lentos y enfermedades por priones. Brooks Geo F. Microbiología médica $18^{\circ}$ Edición. México. Editorial El Manual Moderno. 2005. Pp. 571-7.

3.- OPS 2008. Informe anual de casos de rabia humana y animal en las Américas. Sistema de información epidemiológica (SIEPI). Disponible en: http://www.siepi.panaftosa.org.br/painel. aspx idioma. (accedido: marzo 2010).

4.- OPS 2005. Eliminación de la rabia humana transmitida por perros en América Latina: análisis de la situación, año 2004. Washington. 
73p. Disponible en: http://www.siepi.panaftosa. org.br/painel.aspx idioma. (accedido: marzo 2010).

5.- Favi M, Durán J. Epidemiología de la rabia en Chile (1929-1988) y perspectivas en mamíferos silvestres. Avances en Ciencias Veterinarias. 1991; 6 (1): 13-21.

6.- Favi M, De Mattos C, Yung V, Chala E, López L, De Mattos C. First case of human rabies in Chile caused by an insectivorous bat virus variant. Emerg Infect Dis 2002; 8 (1): 79-81.

7.- $\quad$ Favi M, Yung V, Pavletic C, Ramírez E, De Mattos C C, De Mattos C A. Rol de los murciélagos insectívoros en la transmisión de la rabia en Chile. Arch Med Vet 1999; 31 (2): 157-65.

8.- Núñez F, Favi M, Urcelay V, Sepúlveda C, Fabrega G. Rabia silvestre en murciélagos insectívoros en Chile. Bol. Of. Sanit Panam 1987; 103 (2): 140-5.

9.- Favi M, Catalán. R. Rabia en murciélagos en Chile. Avances en Medicina Veterinaria 1986; 1 (2): 73-6.

10.- Hamilton L. Statistic with Stata 1996. Editorial Duxbury. Printed in Canada.
11.- Campbell M J. Statistic and Square Two. $2^{\text {ed }}$ Ed. Blackwell Publishing (BMJ Books) June. 2006

12.- Favi M, Rodríguez L, Espinosa C, Yung V. Rabia en Chile.1989-2005. Rev Chil Infectol 2008; 25 (Supl): 8-13.

13.- Canals M, Cattan P. Murciélagos en Chile. Canals M y Cattan P. Radiografía a los murciélagos de Chile. Editorial Universitaria. Santiago, Chile 2008. Capítulo VI Pp. 69-84.

14.- Yung V, Fernández J, Favi M. Genetic and antigenic typing of rabies virus in Chile. Arch Virol 2002; 147 (2): 197-205.

15.- Bassaletti A. Descripción epidemiológica de casos diagnosticados positivos al virus de la rabia en la Región Metropolitana, período 2000-2008. Tesis para optar al título profesional de médico veterinario. Santiago, Chile, Universidad Santo Tomás, Escuela de Medicina Veterinaria. 74p.

16.- Vargas R. 2003. Murciélagos y Rabia. Estado de Morelos, México. Disponible en: http//www. hypatia.morelos.gob.mx/no6/colaboraciones/ murciélagos.html. (accedido: marzo 2010).

17.- Hott B. Aplicación de los sistemas de información geográfica en la descripción de conglomerados y en los análisis espaciales, temporal y espacio-temporal de casos de rabia en Tadarida Brasiliensis en la ciudad de Santiago. Período 2000-2002. 2002. Tesis para optar al título profesional de médico veterinario. Santiago, Chile, Universidad Santo Tomás, Escuela de Medicina Veterinaria. $70 \mathrm{p}$.

18.- Rivas A. Análisis espacio-temporal del riesgo de rabia en murciélagos en la Región Metropolitana, durante los años 2000 -2001, 2004. Tesis para optar al título de Médico Veterinario. Santiago Chile Universidad Mayor. $108 \mathrm{p}$.

19.- Kusmin I, Rupprecht Ch. Bat rabies. In Rabies Jackson A and Wunner B. Second Edition 2007 Elsevier Inc Chapter 6 Pp. 259-307.

20.- Wayne M. Epidemiología Veterinaria: Principios y Métodos 1997. Editorial Acribia. Zaragoza. España. 384 p.

21.- CDC. Human rabies-Missouri, 2008. MMWR Morbid Mortal Wkly Rep 2009; 58: 1207-9.

22.- CDC. Human rabies-Kentucky/Indiana, 2009. MMWR Morbid Mortal Wkly Rep 2010; 59: 393-6. 